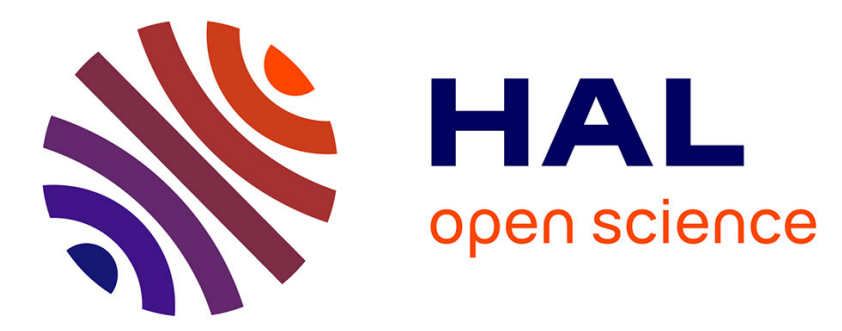

\title{
80-Myr history of buoyancy and volcanic fluxes along the trails of the Walvis and St. Helena hotspots (South Atlantic)
}

Claudia Adam, Valérie Vidal, Javier Escartin

\section{- To cite this version:}

Claudia Adam, Valérie Vidal, Javier Escartin. 80-Myr history of buoyancy and volcanic fluxes along the trails of the Walvis and St. Helena hotspots (South Atlantic). EarthandPlanetaryScienceLetters, 2007, 261, pp.432-442. 10.1016/j.epsl.2007.07.005 . insu-01293891

\section{HAL Id: insu-01293891 https://hal-insu.archives-ouvertes.fr/insu-01293891}

Submitted on 25 Mar 2016

HAL is a multi-disciplinary open access archive for the deposit and dissemination of scientific research documents, whether they are published or not. The documents may come from teaching and research institutions in France or abroad, or from public or private research centers.
L'archive ouverte pluridisciplinaire HAL, est destinée au dépôt et à la diffusion de documents scientifiques de niveau recherche, publiés ou non, émanant des établissements d'enseignement et de recherche français ou étrangers, des laboratoires publics ou privés. 
Elsevier Editorial System(tm) for Earth and Planetary Science Letters

Manuscript Draft

Manuscript Number: EPSL-D-07-00106R1

Title: $80-M y r$ history of buoyancy and volcanic fluxes along the trails of the Walvis and St. Helena hotspots (South Atlantic)

Article Type: Regular Article

Keywords: hotspot, mantle plume, buoyancy fluxes, temporal evolution

Corresponding Author: Dr. Valerie Vidal,

Corresponding Author's Institution: Ecole Normale Superieure de Lyon

First Author: Claudia Adam

Order of Authors: Claudia Adam; Valerie Vidal; Javier Escartin

Abstract: Walvis and St. Helena are the only long-lived hotspot chains in the South Atlantic. Therefore, their characterization is important to constrain the processes associated with mantle plume formation, their temporal evolution, and the interaction with plate and mantle dynamics in the region. We study the temporal evolution of plume buoyancy and magma production rate along both hotspot chains, which are constrained from the swell and volume of volcanic materials emplaced along the chain. The regional depth anomaly is calculated by correcting the 2' bathymetry grid of Smith \& Sandwell (1997, Science, 277) for thermal subsidence and sediment loading. We separate the topography associated with volcanism and the swell surrounding the hotspot chains using the MiFil filtering method (Adam et al., 2005, Geochem. Geophys. Geosyst., 6). We then estimate the temporal variations associated with both parameters by computing volumes along the hotspot tracks. Neither Walvis nor St. Helena show a 'classical' hotspot behavior. We find that two plumes are at the origin of the St. Helena chain. This study also shows a swell associated with the Circe seamount, supporting the existence of a hotspot NW of the St. Helena trail. The variation in swell and volcanic fluxes suggests temporal variability in the plume behavior at time scales of 10-20 m.y. and 5 m.y., which may be related to oscillations and instabilities of the plume conduit, respectively. Cumulative fluxes in 
the area are largest for Walvis and weakest for Circe, and all are significantly lower than that reported for the Hawai'i hotspot. 


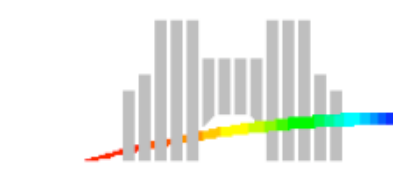

Laboratoire de Physique

Ecole Normale Supérieure de Lyon

46, Allée d'Italie

69364 Lyon cedex 07 - France
CENTRE NATIONAL

SCIENTIFIOUE

Tel: $\quad+33472728561$

Fax: $\quad+33472728080$

E-mail: Valerie.Vidal@ens-lyon.fr

Lyon, June $20^{\text {th }}, 2007$

Dear Editor,

Please find enclosed the revised version of the manuscript entitled "80-Myr history of buoyancy and volcanic fluxes along the trails of the Walvis and St. Helena hotspots (South Atlantic)", by C. Adam, V. Vidal \& J. Escartín (Ms. Ref. No.: EPSL-D-07-00106).

You will find in the "Revision Notes" document the detail of changes and answers to the reviewer's comments.

Faithfully yours,

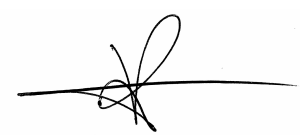

Valérie Vidal

(corresponding author) 


\title{
Revision Notes for the manuscript
}

\author{
"80-Myr history of buoyancy and volcanic fluxes \\ along the trails of the Walvis and St. Helena hotspots (South Atlantic)"
}

by C. Adam, V. Vidal \& J. Escartín

(Ms. Ref. No.: EPSL-D-07-00106)

\section{Answers to general comments}

We agree with the reviewer about the B\&W figures, and regret that it cannot provide the clarity of color figures. We choose to represent both the Walvis and St. Helena chains on a single map (Figure 1), instead of two separated figures (like Figure 2), in order to have in a single view both hotspot chains in the South Atlantic, which is our zone of interest. We think this general view provides a more global idea of the bathymetric region, and enhances the parallel between the St. Helena and Walvis chains study.

We corrected the text for the misspelling and the grammar mistakes. In the following, we give answers to the remarks and suggestions of the reviewer on the paper version, and then, to the specific comments in the review.

\section{Answers to remarks and suggestions on the paper version}

All page numbers refer to the reviewed version.

- p.3-4: we have added in the introduction a paragraph about the swell origin. See answers to question 1 below.

- p.5, second paragraph. Our reference on the ages reported for the Paraná and Etendeka flood basalts was indeed too old. We updated it, and referred to [Gibson et al., 2006].

- p.9, we gave a more detailed explanation for the unclear point about the choice of the main axis.

- p.10, last sentence, St. Helena swell: we clarified the origin of the swell.

- p.10, Walvis swell paragraph: we explained better why the origin of the oldest swells cannot be related to an intraplate setting phenomena (see answer to question 3).

- p.11, the reviewer would prefer to have the discussion on the accuracy of the tracks deduced from the rotation poles and our choice of the linear trends in the previous section (3. Data analysis). But we are basing this discussion on the swells morphology, which are presented in this section (4. Results). We cannot discuss this argument before describing the swells.

- p.11, we removed the repetitive sentence about the choice of the linear trend.

- p.11, the reviewer noticed that the definition of the buoyancy flux is out of place. We agree with his suggestion and moved it to the end of the Data Analysis section. 
- p.12, the reviewer points out that $Q s$ is only defined in the next section. However, we introduced this variable in the third paragraph of the introduction.

- p.15, we added a part discussing the decorrelation of the phenomena responsible for the 10-20 m.y. and the 5 m.y. variations. See answer to question 5.

\section{$\underline{\text { Answers to specific comments }}$}

1. I would expect a swell beneath Hawaii assuming that it is an active hotspot that may have dynamic support from a plume below. But I would not necessarily expect the same for a -50 Myr seamount chain. So I am left wondering what this swell actually is. I think readers like myself would benefit from some discussion of the source of such swells in a section in the introduction.

Usually, dynamic topography is related to the youngest part of the hotspot chain (a few hundred meters in height) and associated with vertical forces due to the plume uplift. The swell at older parts of the hotspot chain may have two origins: 1) A thinner than 'normal' lithosphere, due to reheating at the time the lithosphere was overriding the hotspot plume. This effect vanishes through time, as the lithosphere cools and subsides while it is driven away from the plume. 2) Stocking of plume material within or beneath the lithosphere or crust (underplating), which has a permanent effect. Since no underplating has been identified along St. Helena and Walvis chains, and since the dynamic topography is spatially restricted along these chains, right over the present-day location of the plume head, we attribute the main cause of the swell to the long-term thermal effect of the plume.

We have added a paragraph in the introduction to include these explanations in the article.

2. The authors chose to project data on a straight line through the maxima of the calculated swell, rather than along the seamounts in the chain. I don't think that is a problem, but the rationale for this choice and its ramifications could be better discussed. Does this choice affect the final outcome?

We choose indeed a straight line to model the chain main axis and study the evolution of the volcanic and swell fluxes along this. Our choice is based on the fact that the rotation poles models on the region were unsatisfying. We tried to fit at the same time the volcanoes and the swell emplacement to determine this linear trend. Since it is a subjective criterion, there are of course several possibilities, and the use of these several trends could change the final computed volumes. However, the length of the translating box used for computation is large enough (1000 $\mathrm{km}$ across-track) to include all topographic features and volcanic root spatial extension belonging to the hotspot. This way, the final volumes are very similar regardless of the 'path' chosen for the calculation.

We have clarified this point in section 3. 
3. The authors note that the swells near the continental margin may have a different origin from the other parts of the swell and for this reason, they do not interpret this part of the swell. Again, this choice and the rationale should be discussed a little more. Why is that part of the swell different?

We chose not to interpret the part of the swell at the NE of both St. Helena and Walvis chains because of the irrelevant swell amplitude found, when using the swell computation parameters that are adequate along the main part of the hotspot trends. This result means that it is impossible in this region to interpret the swell as the simple result of the plume expression in an intraplate setting, which predicts a general decrease of the swell amplitude from the younger to the older part of the chain. Moreover, the tectonic analysis of the region shows that the older part of the chains were not formed in an intraplate setting (see section 2.1). Different mechanisms are at stake in the NE part of the hotspot chains, and their interpretation does not enter in the goal of our study.

We have intented to clarify this point in the text (see paragraph after Walvis swell description, in section 4).

4. The authors say that Gough is the likely location of the hotspot. Neither Gough nor Tristan are at the center of the swell. Please explain the choice of Gough a little more.

We do not expect the present-day active volcanism (characterizing the present-day plume head location) to be located at the center of the swell, but at the leading edge of the chain. Indeed, the plume requires some time (typically, a few million years) to influence the thermal structure of the lithosphere, until generating the swell maximum. Hotspot volcanism is associated with the ascent of melt through the lithosphere and to the seafloor, and therefore occurring "upstream" from the swell maximum. Gough satisfies this criterion, which is moreover observed for other hotspots, the French Polynesia being another well-known example [e.g. Adam et al., 2005].

We have added a clarification for this point in section 4, right after the swells description, when justifying the choice of our linear trend.

5. In the discussion, the authors explain the 10-20 Myr variability by breaking up of the plume into blobs because of tilting. Then they describe the $\sim 5 \mathrm{Myr}$ variation as solitary waves in the conduit. The rationale behind this dichotomy is not explained. Please tell the reader why you ascribe one wavelength to one cause and another wavelength to another cause.

We agree that no objective criterion makes it possible to decorrelate the phenomena responsible for the 10-20 m.y. and the 5 m.y. variations. What we want to point out in the discussion are the possible physical mechanisms that could be responsible for such observations.

We clarified this point at the end of section 5.1. 


\title{
80-Myr history of buoyancy and volcanic
} fluxes along the trails of the Walvis and St. Helena hotspots (South Atlantic)

\author{
Claudia Adam ${ }^{\mathrm{a}, *}$, Valerie Vidal ${ }^{\mathrm{b}}$, Javier Escartín ${ }^{\mathrm{c}}$ \\ ${ }^{a}$ Institute for Research on Earth Evolution, Japan Agency for Marine-Earth \\ Science and Technology, 2-15 Natsushima, Yokosuka, 237-0061, Japan \\ ${ }^{\mathrm{b}}$ Laboratoire de Physique, Ecole Normale Supérieure de Lyon-CNRS, 46 Allée \\ d'Italie, 69364 Lyon cedex 07, France \\ ${ }^{\mathrm{c}}$ Laboratoire de Géociences Marines - CNRS, Institut de Physique du Globe de \\ Paris, case 89, 4 place Jussieu, 75252 Paris cedex 05, France
}

\begin{abstract}
Walvis and St. Helena are the only long-lived hotspot chains in the South Atlantic. Therefore, their characterization is important to constrain the processes associated with mantle plume formation, their temporal evolution, and the interaction with plate and mantle dynamics in the region. We study the temporal evolution of plume buoyancy and magma production rate along both hotspot chains, which are constrained from the swell and volume of volcanic materials emplaced along the chain. The regional depth anomaly is calculated by correcting the 2' bathymetry grid of Smith \& Sandwell (1997, Science, 277) for thermal subsidence and sediment loading. We separate the topography associated with volcanism and the swell surrounding the hotspot chains using the MiFil filtering method (Adam et al., 2005, Geochem. Geophys. Geosyst., 6). We then estimate the temporal variations associated with
\end{abstract}


both parameters by computing volumes along the hotspot tracks. Neither Walvis nor St. Helena show a 'classical' hotspot behavior. We find that two plumes are at the origin of the St. Helena chain. This study also shows a swell associated with the Circe seamount, supporting the existence of a hotspot NW of the St. Helena trail. The variation in swell and volcanic fluxes suggests temporal variability in the plume behavior at time scales of 10-20 m.y. and 5 m.y., which may be related to oscillations and instabilities of the plume conduit, respectively. Cumulative fluxes in the area are largest for Walvis and weakest for Circe, and all are significantly lower than that reported for the Hawai'i hotspot.

Key words: hotspot, mantle plume, buoyancy fluxes, temporal evolution PACS: 91.45.Fj, 91.45.Jg, 91.50.Ga, 93.30.Mj

\section{$1 \quad 1$ Introduction}

2 Hotspot chains are the result of the interaction of stationary zones of man3 tle upwelling (plumes) with an overlying drifting plate [1]. Two main surface 4 manifestations are generally associated with such a plume-lithosphere interac5 tion: (1) a prominent volcanic chain which displays a linear age progression, 6 as plate motion drags the seamounts away from their zone of emplacement 7 above the plume; and (2) a large positive depth anomaly (typically 100's of 8 kilometers in extent and $\sim 100$ 's of meters in height) called a swell [2]. The 9 hotspot swells may be produced by several phenomena. Dynamic topography,

* Corresponding author.

Email addresses: adam@jamstec.go.jp (Claudia Adam), Valerie.Vidal@ens-lyon.fr (Valerie Vidal), escartin@ipgp.jussieu.fr (Javier Escartín). 
associated with vertical forces due to plume uplift, may generate a swell (a few hundred meters in height) in the youngest part of the hotspot chain, where the lithosphere drifts over the plume head. The swell at older parts of the hotspot chain may have two origins: 1) A thinner than 'normal' lithosphere, due to reheating at the time the lithosphere was overriding the hotspot plume. This effect vanishes through time, as the lithosphere cools and subsides while it is driven away from the plume. 2) Stocking of plume material within or beneath the lithosphere or crust (underplating), which has a permanent effect. Since no underplating has been identified along St. Helena and Walvis chains, and since the dynamic topography is spatially restricted along the youngest part of these chains, we attribute the main cause of the swell to the long-term thermal effect of the plume.

The swell is a direct consequence of the buoyant plume upwelling, and therefore, it is commonly used as the parameter to quantify the hotspot strength $[3-5]$. However, this parameter is inadequate to study the history of a hotspot chain and the underlying plume dynamics, as the swell amplitude decreases with time due to lithospheric cooling. The volcanic material accumulated along the hotspot chain, which is not affected by this cooling, is a direct record of the volcanic output to the seafloor. However, while being a good indicator of hotspot activity, the volume of extrusives may somewhat underestimate the total melt production, as other processes may operate such as melt entrapment in deep lithospheric levels, or lateral melt migration (i.e., lithospheric cracks) and emplacement away from the volcanic chain. The combined analyses of both swell and volcanic volumes accumulated along the chain is therefore most adequate and necessary to constrain long-term plume activity [5].

In this study, we use the available bathymetric [6], sediment thickness and 
seafloor age data [21] to correct for thermal subsidence and sediment loading, and obtain a seafloor depth anomaly around the Walvis and St. Helena hotspot chains. We then separate the swell and volcanic topography components from the residual bathymetry [7]. We then estimate the temporal evolution in production rate of volcanic material $Q_{v}$ (including both the volcanic edifices and compensating root due to plate flexure) and in the swell flux $Q_{s}$. We compare these results with those from Hawai'i [5], the most typical example of a hotspot chain.

\section{Tectonic setting}

\subsection{Description of the Walvis and St. Helena chains}

Walvis and St. Helena are the two main hotspot chains found in the South Atlantic. They are formed by wide and continuous zones of diffuse volcanism (oceanic islands, seamounts and small ridges), that locally reach a width of more than $500 \mathrm{~km}$. It is generally considered that these volcanic chains have been created by mantle plumes interacting with the overlying African plate, and that the locus of present-day activity is situated in the proximity of the Islands of Tristan da Cunha for the Walvis Ridge. For St. Helena, the youngest age of volcanism (2.6 Ma) is reported at Josephine seamount $[4,8]$ (see Figure 1). This is consistent with the reported general age progression of volcanism away from the St. Helena and Gough islands and towards the African continent $[9,10]$.

The Walvis Ridge extends WSW some $2800 \mathrm{~km}$ from the southwest African continental margin towards the Mid-Atlantic Ridge near Tristan da Cunha 
and Gough islands (Figure 1). Based on morphological and structural characteristics, the chain displays different tectonic settings at the time of volcanic emplacement and loading. The northeastern part (east of $3^{\circ} \mathrm{E}$ ) has a ridge-like, elongated morphology rising 2-3 km above the surrounding seafloor. Largescale block faulting in this area is prominent, as inferred from the gravity, bathymetry and seismic data $[13,14]$. Further southwest, the ridge splits into two branches, one trending N-S and a second one trending NE-SW, both composed of individual seamounts and guyots. The N-S trending branch terminates near $34^{\circ} \mathrm{S}$, whereas the oblique branch continues WSW towards the present-day hotspot location on the eastern flank of the Mid-Atlantic Ridge.

The initial manifestation of the Walvis hotspot occurred at the opening of the South Atlantic 130 Ma ago, when it contributed to the emplacement of the Paraná (Southeast Brazil) and Etendeka (southwest Africa) flood basalts, 127.5 to $139 \mathrm{Ma}$ old [15]. The hotspot was located initially on the American plate, crossed the axis 80-70 Ma ago, and progressively separated from it to its present-day location on 7 Ma-old African plate.

Evidence for this transition from on-axis to intraplate volcanism is found in many geophysical and geochemical observables. The geochemical analyses evidence a westward migration of the spreading axis, away from the plume $[9,16]$. The structural differences between the northeast (oldest) and southwest (youngest) sections of the chain are also reflected in their compensation mechanisms. While the older part is compensated by over-thickening of the oceanic crust $[13,14]$, the western part is instead regionally compensated by the bending of a lithosphere with an effective elastic thickness of 5-8 km [14]. These different compensation mechanisms reflect the transition with time from a near-axis emplacement with a thin lithosphere and over-thickened crust to an 
intraplate setting with a thicker lithosphere. This transition is also observed in the mode of volcanic emplacement, that produces a province of intermittent, isolated volcanism rather than a structurally continuous ridge.

The St. Helena chain is less well-defined, and is characterized by a broad and ill-defined band of scattered seamounts and volcanic ridges, with a shorter history than that of Walvis, but with a similar progressive separation of the hotspot from the axis. The oldest dated sample along the St. Helena chain is $81 \mathrm{Ma}$ [10], dredged on a seamount situated at the northeastern extremity of the chain (Figure 1). The Cameroon line, northeast of this volcano, seems to form a bathymetric extension of the St. Helena chain into the Gulf of Guinea and linking with the African continent. However, the Cameroon lineament does not show any age progression [17], and therefore cannot be directly linked to a hotspot origin. The origin of the St. Helena chain on the African plate is associated with the emplacement of the Brazilian seamounts on the American plate [10]. Geochemical [16,18] and seismological studies [19] indicate a migration of the St. Helena plume toward the spreading axis. Circe seamount (Figure 1) has been proposed as the site of an active hotspot by Schilling et al. [16]. It is dated at 6.6 Ma, and may be part of a hotspot trail whose present-day location should be some $130 \mathrm{~km}$ SW of Circe seamount [8].

\subsection{Age evolution}

The distribution of the available volcanic ages (Figure 1) shows a large scatter, with many volcanic edifices located in the same area displaying differences in age of more than $10 \mathrm{Ma}$. For example, at $34^{\circ} \mathrm{S}$, we observe a $44.6 \mathrm{Ma}$ volcanic age between sites dated at 64.4 Ma (south) and 61.6 Ma (north). This 
age scattering can be explained by diffuse volcanism, due either to a broad plume (several hundreds of $\mathrm{km}$ in diameter) or the presence of a cluster of plumes [9]. Independent geophysical data support the latter hypothesis, since numerous small-wavelength elongated features appear in filtered geoid and topography maps [20], which could indicate the presence of multiple narrow plumes. The likely presence of additional hotspot chains in nearby areas, such as the Circe seamount and proposed associated trail, is consistent with the probable presence of several hotspots $[8,16]$.

Some features uncorrelated with the Walvis and St. Helena plumes have also been reported, as Vema (18 Ma) and 7 East (91 Ma) seamounts south of the Walvis chain. Haxel \& Dziak [12] have detected volcano-acoustic signals around a seamount situated on the northern edge of the Walvis track at $5.22^{\circ} \mathrm{W}$ $32.96^{\circ} \mathrm{S}$ (see Figure 1). These signals are interpreted as volcanogenic explosions suggesting present-day magmatic activity. The authors support the hypothesis that this phenomenon is not directly related to the Walvis mantle plume, but rather to extensional fracture zones along inactive segments of the chain.

The Walvis and St. Helena chains may have recorded the decrease in velocity of the African plate, that occurred between 19 and 30 Ma [8]. According to O'Connor et al. [8], the migration rate along the St. Helena chain changed from $30 \mathrm{~mm} / \mathrm{yr}$ to $20 \mathrm{~mm} / \mathrm{yr}$ at $19 \mathrm{Ma}$. This change occurred at $30 \mathrm{Ma}$ along the Walvis chain, with a reduction from $31 \mathrm{~mm} / \mathrm{yr}$ to $22 \mathrm{~mm} / \mathrm{yr}$. However, the plate velocity diminution has been computed considering that the chain follows a continuous NW direction [8], without taking into account hotspot tracks deduced from the rotation poles. Moreover, the slowdown is estimated solely on the two younger ages available for each chain, and is therefore poorly constrained. 


\section{Data analysis}

We first compute the depth anomaly throughout the study area. Using the global age grid of Müller et al. [21] and the GDH1 thermal subsidence model of Stein \& Stein [22], we compute the thermal subsidence, which we substract from the bathymetry [6] (Figure 1). The resulting depth anomaly is then corrected for sediment loading (see [7] for computational details), to obtain the residual bathymetry. In order to test different cooling models, we have also performed the computation with the Parsons \& Sclater [23] thermal subsidence model. The results (e.g., flux vs. time estimates) are shifted relative to each other but preserve the variations and their amplitudes [5]. Interpretation of the buoyancy and volcanic flux variations in time are therefore independent of the thermal model used, even if their absolute value remains unconstrained.

In order to separate the swell $\left(H_{S}\right)$ and volcanic edifices $\left(H_{V}\right)$ components from the resulting depth anomaly grid, we adapted the MiFil method developped by Adam et al. [7]. This low-pass filtering method effectively removes the topography associated with volcanic edifices from the depth anomaly, and gives the topography corresponding to the swell component $H_{S}$, as shown for the St. Helena and the Walvis chains in Figures 2a and 2b, respectively. The volcanic component $H_{V}$ is thus the difference between the residual bathymetry and the swell component $H_{S}$.

The $H_{S}$ and $H_{V}$ data can then be used to compute both the swell volume and the volume of erupted material (volcanic edifices). The swell volume corresponds to the volume between the reference depth anomaly (zero) and the swell $H_{S}$. To estimate the volume of erupted material, we consider the vol- 
canic topography, and calculate the associated compensating root. We assume that the volcanic loading is supported by an elastic lithosphere [26] with an elastic thickness of $7 \mathrm{~km}$, as deduced from the age of the crust at the time of loading. Note that the choice of this compensation (regional), rather than a local (Airy) compensation, does not have a significant influence on the final results, as the computed volcanic volumes are unchanged [5].

We then compute the variation of the buoyancy $\left(Q_{S}\right)$, inferred from swell volume variations [3], and volcanic $\left(Q_{V}\right)$ fluxes through time for each of the two volcanic chains in a fashion similar to that of Vidal \& Bonneville [5]. We translate a rectangular box of fixed size $(1000 \mathrm{~km}$ long across-track and $20 \mathrm{~km}$ wide along-track) along the main axis of the chains to compute the variation of the swell and volcanic material along this trend. We chose to approximate the main axis by the straight traces shown in Figure 2, since the hotspot tracks calculated from rotation poles $[9,24,25]$ do not match either the swell or the volcanic chain trends. The length of the computing box, in the direction transverse to the trend, is taken large enough $(1000 \mathrm{~km})$ to include all the topographic features created by the hotspot and/or all its volcanic root. Therefore, volume calculations are scarcely affected by using other paths (e.g. theoretical hotspot track) for our computation instead of the straight line presented here [5].

We also introduce the buoyancy flux $(B)$ temporal evolution along the main axis trends. The buoyancy flux is commonly used to quantify the rate of swell formation [3]:

$$
B=\left(\rho_{m}-\rho_{w}\right) A V_{p}
$$


where $\rho_{m}$ and $\rho_{w}$ are mantle and seawater densities respectively, $A$ is the area of the swell in a vertical plane transverse to the hotspot track, and $V_{p}$ the plate velocity in the hotspot frame. $B$ can therefore be written as $B=\left(\rho_{m}-\rho_{w}\right) Q_{s}$.

\section{Results}

We identify swells associated with both the St. Helena and Walvis chains, and an additional one associated with the Circe seamount (Figure 2), north of St. Helena's trail.

St. Helena swell - The St. Helena swell is composed of two circular highs, one centered at longitude $6.5^{\circ} \mathrm{W}$, the other at longitude $9^{\circ} \mathrm{W}$ (Figure $2 \mathrm{a}$ ). This observation suggests that two plumes may be at the origin of the St. Helena chain. It is also interesting to note that the dated volcanoes are located slightly south of these maxima, indicating a probable influence of weakness zones of the lithosphere. The strong increase in swell amplitude, northeast of the chain ( $>50 \mathrm{Ma}$ ), will not be discussed further here, since its origin is not related to a plume, but more probably to continental processes (see section 2.1).

Circe swell - The swell has a maximum $\sim 400 \mathrm{~m}$ amplitude and a 300-400 km width (Figure 2a). The swell maximum is located $150 \mathrm{~km} \mathrm{SW}$ of the $6.6 \mathrm{Ma}$ Circe seamount, which is part of an independent hotspot trail, as suggested by O'Connor et al. [8].

Walvis swell - The Walvis chain shows several maxima along its track. The high associated with the presumed present-day hotspot location has an amplitude of $\sim 1400 \mathrm{~m}$ and a diameter $>500 \mathrm{~km}$, with a maximum located NE of Gough Island and ESE of Tristan da Cunha (Figure 2b). The dated volcanoes 
are here again located on the edge of the swell and not on its maximum. The middle section of the track, between $28^{\circ} \mathrm{S}$ and $37^{\circ} \mathrm{S}$, shows two adjacent swells, with a somewhat smaller amplitude of $\sim 1200 \mathrm{~m}$, and a width of $\sim 400 \mathrm{~km}$. The easternmost swell is elongated along a SW-NE direction, whereas the western one has a trend close to the NS direction. Note that both trends are parallel to the volcanic chain.

Important swell amplitudes are found in the NE part of both St. Helena and Walvis chains (Figure 2). Considering the ages of the volcanism associated with this part of the chains, these older swells (>50 Ma for St. Helena and >65 Ma for Walvis) have a too important amplitude to be considered as the result of the plume expression in an intraplate setting (see section 2.1). Indeed, after the plume reheating, the lithosphere cools and subsides, and the subsequent mean swell amplitude should decrease. Figure 2 shows that the swell in the older part of both chains does not follow this tendency, thus indicating that other physical processes are at stake. Therefore, the parameters we used to characterize the Walvis and St. Helena hotspot swells are not adequate to characterize the NE depth anomaly, which implies different phenomena, maybe of continental origin, occurring at different spatial scales [27]. Hence, these parts of the swells (>50 Ma for St. Helena and >65 Ma for Walvis) will not be further studied.

The hotspot tracks, deduced from rotation poles (displayed in Figure 2b), match only the overall alignment and orientation of the swells along the central and northeasternmost portions of the chain, but are not consistent with the location of the swell at the southwesternmost end of the chain (Figure 2b). Indeed, all the models choose Tristan da Cunha as the present-day location of the plume, whereas the swell morphology clearly indicates that Gough is the most probable origin. Note that the shift between the plume head em- 
placement and the swell maximum is a classical feature of a hotspot chain. Indeed, the plume requires some time (typically, a few million years) to influence the thermal structure of the lithosphere, and hence generates a swell whose maximum is located a few hundred kilometers from the present-day plume head location, in the direction of plate motion (NE, here). On the other hand, hotspot volcanism is associated with the ascent of melt over the plume head, through the lithosphere and to the seafloor, and hence occurring 'upstream' from the swell maximum. Gough is therefore the best candidate for the present-day Walvis plume location. Since the tracks deduced from rotation poles do not accurately describe the plume trajectory, we choose to describe it by the linear trends displayed in Figures $2 \mathrm{a}$ and $2 \mathrm{~b}$. We assume a linear age progression of volcanism due to the drift of the African plate along them.

Figure 3 shows the swell amplitude along the trend, as a function of distance from the zone of active volcanism. The reported ages of volcanism $[9,10]$ show an overall age progression, but the large scatter in the data suggests that the chain formation is complex, with active volcanism extending over a large area. Distance along the proposed axes of both chains can be used as a proxy for age if we assume a constant velocity of the African plate of $29 \mathrm{~mm} \mathrm{yr}^{-1}$ [8]. O'Connor et al. [8] also report a substantial deceleration of the African plate speed at 20-30 Ma, but this event is poorly constrained, and is not systematically observed in other plate motion models $[9,24,25]$. We thus chose to extrapolate the volcanic ages along the trend (bottom $x$-axis in Figures 3 and 4), with a constant migration rate of $29 \mathrm{~mm} \mathrm{yr}^{-1}$. We also represent in Figure 4 the buoyancy flux $B$, commonly used to quantify the rate of swell formation (see section 3).

The swell along the volcanic chains (Figure 3) does not display the typical 
decay in amplitude with distance (age) from the present-day position of the hotspot. We observe instead a maximum in the swell amplitude at $\sim 800 \mathrm{~km}$ ( $\sim 30 \mathrm{Ma})$ and $\sim 500 \mathrm{~km}(\sim 15-20 \mathrm{Ma})$ along St. Helena and Walvis track, respectively. Note that the width of the swell profile along the St. Helena track is due to the presence of two swell maxima, slightly shifted off-axis (see above section, and Figure 2a). Another large bump is observed along the Walvis chain, between 35 and 60 Ma. In the next section, we analyse the temporal variations of the deduced buoyancy fluxes.

\section{Discussion}

\subsection{Temporal evolution of plume fluxes}

\section{Swell flux $Q_{s}-$}

The calculated buoyancy fluxes as a function of volcanic age are shown in Figure 4. For St. Helena, we observe a single wide bump centered at $\sim 30 \mathrm{Ma}$, whose width can be explained by the presence of two adjacent swells (see previous section). We observe several maxima in the swell flux along the Walvis chain: a marked maximum at $\sim 10 \mathrm{Ma}$ and two additional ones of smaller amplitude at 38 and 54 Ma. These secondary maxima are subdued in Figure 4, due to the scaling, but they are well-visible on the Walvis swell map (Figure $2 \mathrm{~b}$ ). The older parts of the buoyancy flux ( $>50$ Ma for St. Helena and $>65$

Ma for Walvis) are not interpreted (see swell amplitude discussion, section 4).

The Hawai'i chain, which has a shorter life span $(<45 \mathrm{Ma})$ than that of the St. Helena ( $\sim 60 \mathrm{Ma})$ and Walvis chains $(\sim 80 \mathrm{Ma})$, is probably the best 
characterized hotspot trail [5], and can be used as a reference in our study. Note that we ignore here the Emperor part, where no swell is reported, and whose volcanic flux is much smaller [5]. Hawai'i shows two important peaks at 3 and 15 Ma. It is important to note that the 3 Ma peak may not be a "real" one since plumes require some time (typically a few million years) to influence the thermal structure of the lithosphere. The swell may then not be totally formed yet at the youngest extremity. Therefore, the age difference between the two peaks in the Hawaiian swell (Figure 4, bottom) could still increase in the next few million years.

\section{Volcanic flux -}

The St. Helena chain displays a peak at $10 \mathrm{Ma}$, preceded by another peak at $30 \mathrm{Ma}$, in the magma production rate $Q_{v}$. Based on both the lack of correlation between variations in $Q_{v}$ and $Q_{s}$ (Figure 4), and on the presence of two marked swells (Figure 2a), we propose that the St. Helena trail is formed by two hotspots, instead of a single one. Recent evidence of the existence of two plumes beneath the younger part of St. Helena chain, given by tomography [28], favor this hypothesis.

The Walvis chain also shows a peak at $10 \mathrm{Ma}$ in the magma production rate $Q_{v}$, correlated with the main peak in the buoyancy flux profile (Figure 4). This main peak is preceded by two secondary peaks in $Q_{v}$, at 39 and $59 \mathrm{Ma}$, also correlated with two smaller peaks in $Q_{s}$ at 38 and $54 \mathrm{Ma}$ (Figure 4 and above discussion on $Q_{s}$ ). This correlation between $Q_{v}$ and $Q_{s}$ strongly suggests a common origin for both fluxes, with a single plume that peaked in activity at $10 \mathrm{Ma}$ with pulsations 10-20 Ma apart. These pulsations are superimposed on an apparent long-term waning of the plume. We see indeed a progressive 
overall decrease in $Q_{v}$ since a maximum at about $60 \mathrm{Ma}$. This decrease in the volcanic activity is also apparent in the progressive diminution of the size and density of seamounts at the seafloor (Figure 1). In comparison, the production of magma increases drastically during the last $30 \mathrm{Ma}$ for Hawai'i (Figure 4). A peak is observed at $15 \mathrm{Ma}$ along this chain with a pronounced increase to the present time, suggesting that the plume is waxing and may have not reached yet its maximal activity.

Both St. Helena and Walvis show short-term variations in magma production rate $Q_{v}$, with a periodicity of about 5 m.y., which has also been reported for Hawai'i [5].

\section{Evolution of fluxes -}

The most significant result of this study is that the Walvis plume does not appear to be steady state, but rather shows pulsations at 10-20 m.y.. This periodicity cannot be determined for St. Helena, as it is likely the result of the activity of two plumes and their temporal variations. A possible explanation for these pulsations is the tilt of the plume conduit due to large-scale mantle advection [11,29], as they may develop oscillations if their dip is larger than $60^{\circ}$ [29]. This mechanism has been also invoked to explain the scatter in volcanic ages along other hotspot chains such as Louisville [30]. In this study, we suggest that the observed periodicity of 10-20 m.y. may be the first estimate of the frequency of these oscillations, deduced from observed data.

Walvis also shows a marked decrease in volcanic flux $Q_{v}$ through time which may reflect a progressive and steady waning of the plume and its associated activity during the last $60 \mathrm{Ma}$ or more; its extinction could occur in $30 \mathrm{Ma}$ if this decline continues at a similar rate. The Walvis plume conduit is not 
imaged by tomography models [31,32], which may be also an indicator of its weakening and possible extinction. Alternatively, there is a progressive increase of the age of the lithosphere over which the volcanism is emplaced due to the migration of the ridge away from the hotspot. The resulting thickening of the lithosphere with time could play a role in this reduction of $Q_{v}$, but this interpretation is not supported by the lack of such a pattern along the St. Helena chain.

The shorter-term variations with a periodicity of $\sim 5$ m.y. observed in the magma production rate $Q_{v}$ for St. Helena and Walvis (Figure 4) have a too small periodicity to be associated with a plume tilting phenomenon, which can sustain tilts up to $60^{\circ}$, depending on the surrounding mantle viscosity [11]. No evidence of the decorrelation of both the 10-20 and 5 m.y. pulsations can be affirmed. One possible explanation, however, could be the presence of solitary waves within the plume conduit [33]. These perturbations have been invoked to explain both isotopic heterogeneities [34] and a similar 5-7 m.y. periodicity in volcanism [5] along the Hawai'i chain (Figure 4).

\subsection{Total volumes and fluxes}

We have computed the cumulative volcanic and swell volumes for the St. Helena and Walvis chains, and reported the estimation of swell volume for Circe in Table 1; owing to the lack of data, we cannot provide an estimate of its volcanic flux. In Table 1 are also reported the values found for Hawai'i (from [5]). We have also calculated the mean fluxes along each chain, which we pre-

fer over the present-day values normally reported in the literature, as they integrate the activity and strength of hotspots over their lifespan. 
Hawai'i has the greatest mean volcanic and swell fluxes, thus indicating that it is the most vigorous of all the identified plumes. Walvis and St. Helena have similar volcanic fluxes but Walvis' swell flux is three times greater than that of the St. Helena system. As St. Helena results from the combination of two plumes, we can deduce that these are two small ones. The low swell flux associated with Circe suggests that it is a weak and/or small plume.

\section{Conclusion}

In this paper we have presented the first characterization of the swell and volcanic fluxes and their temporal evolution along the Walvis and St. Helena hotspot trails. Both hotspot trails are associated with very broad swells, with the volcanic activity slightly offset relative to the swell maxima. For Walvis, the swell maximum shows a marked offset with respect to the proposed present-day hotspot location inferred from rotation pole reconstruction (Tristan da Cunha), suggesting that the trajectory of this plume is not accurately described by these models. We propose that Gough is the most probable present-day hotspot location. We also find a modest swell associated with the Circe seamount, north of the St. Helena trail, supporting the proposed presence of a hotspot whose location is still undetermined, and an associated volcanic chain.

The Walvis hotspot appears to be the result of a single, waning plume, that shows variations in the volcanic and swell flux at a 10-20 m.y. time-scale, and additional, shorter-term variations of about 5 m.y. in the volcanic flux. In contrast, the St. Helena chain appears to be the result of two hotspots, which precludes the interpretation of calculated volcanic and swell fluxes in terms 
of temporal variability of a single plume. This chain shows also a volcanic periodicity of 5 m.y., similar to that observed along the Hawai'i chain. The 10-20 m.y. periodicity may be due to the tilting of the mantle plume conduit under mantle advection, whereas the 5 m.y. variabilities could be explained by instabilities in the conduit itself.

The estimation of the mean swell and volcanic fluxes makes it possible to compare the relative strength of the South Atlantic plumes. The strongest is Walvis, followed by the two St. Helena plumes, and probably Circe. The Hawai'i plume (Pacific), which is the reference hotspot in our study, remains the most vigorous among all these plumes.

Acknowledgments This work is partially supported by a Grant-in-Aid for Scientific Research (16253002) from the Japan Society for the Promotion of Science (C. Adam), and benefited from a CNRS/ATI grant to J. Escartín. Discussions with M. Cannat, J. Lin, G. Ito and Y. Fukao during the early stages of the project contributed to its development and completion. We are grateful to J. O'Connor for kindly answering questions about the African plate motion and age reliability, and F. Vivanco for his help in data transfer. Comments by the editor G. D. Price and reviewer W. Sager greatly helped us to clarify and improve this manuscript.

\section{References}

[1] J. Wilson, A possible origin of the Hawaiian Islands, Canadian J. Phys. 41 (1963) 863-870.

[2] S. Crough, Hotspot swells, Ann. Rev. Earth Planet. Sci. 11 (1983) 165-193. 
[3] N. Sleep, Hotspots and mantle plumes: some phenomenology, J. Geophys. Res. 95 (1990) 6715-6736.

[4] V. Courtillot, A. Davaille, J. Besse, J. Stock, Three distinct types of hotspots in the Earth's mantle, Ann. Rev. Earth Planet. Sci. 205 (2003) 295-308.

[5] V. Vidal, A. Bonneville, Variations of the Hawaiian hot spot activity revealed by variations in the magma production rate, J. Geophys. Res. 109 (2004) B03104, doi:10.1029/2003JB002559.

[6] W.H.F. Smith, D.T. Sandwell, Global sea floor topography from satellite altimetry and ship depth soundings, Science 277 (1997) 1956-1962.

[7] C. Adam, V. Vidal, A. Bonneville, MiFil: A method to characterize seafloor swells with application to the south central Pacific, Geochem. Geophys. Geosyst. 6 (1) (2005) Q01003, doi: 10.1029/2004GC000814.

[8] J.M. O'Connor, P. Stoffers, P. van den Bogaard, M. McWilliams, First seamount age evidence for significantly slower African plate motion since 19 to $30 \mathrm{Ma}$, Earth Planet. Sci. Lett. 171 (1999) 575-589.

[9] J.M. O'Connor, R.A. Duncan, Evolution of the Walvis Ridge-Rio Grande Rise Hot Spot System: Implications for African and South America Plate Motions Over Plumes, J. Geophys. Res. 95 (1990) 17,475-17,502.

[10] J.M. O'Connor, A.P. le Roex, South Atlantic hot spot plume systems: 1. Distribution of volcanism in time and space, Earth Planet. Sci. Lett. 113 (1992) $17,343-17,364$.

[11] B. Steinberger, Plumes in a convecting mantle: Models and observations for individual hotspots, J. Geophys. Res. 105 (2000) 11,127-11,152.

[12] J.H. Haxel, R.P. Dziak, Evidence of explosive seafloor volcanic activity from the Walvis Ridge, South Atlantic Ocean, Geophys. Res. Lett. 32 (2005) L13609, doi: 10.1029/2005GL023205. 
[13] J. Goslin, J.C. Sibuet, Geophysical study of the easternmost Walvis Ridge, South Atlantic: Deep structure, Geol. Soc. Am. Bull. 86 (1975) 1713-1724.

[14] R.S. Detrick, A.B. Watts, An analysis of Isostasy in the World's Oceans, 3. Aseismic Ridges, J. Geophys. Res. 84 (1979) 3637-3653.

[15] S.A. Gibson, R.N. Thompson, J.A. Day, Timescales and mechanisms of plumelithosphere interactions: ${ }^{40} \mathrm{Ar} /{ }^{39} \mathrm{Ar}$ geochronology and geochemistry of alkaline igneous rocks from the Paraná-Etendeka large igneous province, Earth Planet. Sci. Lett. 251 (2006) 1-17.

[16] J.-G. Schilling, G. Thompson, R. Kingsley, S. Humphris, Hotspot-migrating ridge interaction in the South Atlantic, Nature 313 (1985) 187-191.

[17] J.G. Fitton, The Cameroon Line, West Africa: a comparison between oceanic and continental alkaline volcanism, Geol. Soc. London Spec. Publ. 30 (1987) $273-291$.

[18] J.-G. Schilling, Upper mantle heterogeneities and dynamics, Nature 314 (1985) $62-67$.

[19] Y.-S. Zhang, T. Tanimoto, Ridges, hotspots and their interactions as observed in seismic velocity maps, Nature 355 (1992) 45-49.

[20] L. Fleitout, C. Dalloubeix, C. Moriceau, Small-wavelength geoid and topography anomalies in the South Atlantic Ocean: A clue to new hot-spot tracks and lithospheric deformation, Geophys. Res. Lett. 16 (1989) 637-640.

[21] D.M. Müller, W.R. Roest, J.-Y. Royer, L.M. Gahagan, J.G. Sclater, Digital isochrons of the world's ocean floor, J. Geophys. Res. 102 (1997) 3211-3214.

[22] C. Stein, S. Stein, A model for the global variation in oceanic depth and heat flow with lithospheric age, Nature 359 (1992) 123-129. 
[23] B. Parsons, J. Sclater, An analysis of the variation of ocean floor bathymetry and heat flow with age, J. Geophys. Res. 82 (1977) 803-827.

[24] R. A. Duncan, M.A. Richards, Hotspots, mantle plumes, flood basalts and true polar wander, Rev. Geophys. 29 (1991) 31-50.

[25] R.D. Müller, J.-Y. Royer, L.A. Lawver, Revised plate motions relative to the hotspots from combined Atlantic and Indian Ocean hotspot tracks, Geology 21 (1993) 275-278.

[26] A. Watts, J. Cochran, G. Selzer, Gravity anomalies and flexure of the lithosphere: A three-dimensional study of the Great Meteor Seamount, northeast Atlantic, J. Geophys. Res. 80 (1975) 1391-1399.

[27] W.J.M. Van der Linden, Walvis Ridge, a piece of Africa?, Geology 8 (1980) $417-421$.

[28] R. Montelli, G. Nolet, F.A. Dahlen, G. Masters, A catalogue of deep mantle plumes: New results from finite-frequency tomography, Geochem. Geophys. Geosyst. 7 (2006) Q11007, doi10.1029/2006GC001248.

[29] J. Whitehead, Instabilities of fluid conduits in a flowing Earth - Are plates lubricated by the asthenosphere ?, Geophys. J. R. Astr. Soc. 70 (1982) 415433.

[30] A.A.P. Koppers, R.A. Duncan, B. Steinberger, Implications of a nonlinear ${ }^{40} \mathrm{Ar} /{ }^{39} \mathrm{Ar}$ age progression along the Louisville seamount trail for models of fixed and moving hot spots, Geochem. Geophys. Geosyst. 5 (2004) Q06L02, doi: 10.1029/2003GC000671.

[31] R. Montelli, G. Nolet, F.A. Dahlen, G. Masters, E.R. Engdahl, S. Hung, Finitefrequency tomography reveals a variety of plumes in the mantle, Science 303 (2004) 338-343. 
475

[32] C. O'Neill, D. Müller, B. Steinberger, On the uncertainties in hot spot reconstructions and the significance of moving hot spot reference frames, Geochem. Geophys. Geosyst. 6 (2005) Q04003, doi:10.1029/2004GC000784.

[33] J. Whitehead, K. Helfrich, Magma waves and diapiric dynamics, in Magma transport and storage, ed. M. Ryan (John Wiley \& Sons, 1990).

[34] H. West, D. Gerlach, W. Leeman, M. Garcia, Isotopic constraints on the origin of Hawaiian lavas from the Maui Volcanic Complex, Hawaii, Nature 330 (1987) $216-219$. 


\section{FIGURE \& TABLE CAPTIONS}

Fig. 1. Bathymetry of St. Helena and Walvis chains (2' bathymetry grid from [6]), and published volcanic ages (in million years, from $[9,10]$ ). Black lines indicate the traces used to study the temporal evolution of hotspot fluxes (see text for discussion). The white and black stars indicate the present-day location of the Walvis plume inferred by Courtillot et al. [4] and Steinberger [11], respectively. The white dot on Walvis northern edge indicates the location of presumed present-day underwater volcanism as inferred from hydrophone events [12].

Fig. 2. Calculated swell associated with the St. Helena and Walvis chains. a) Numbers correspond to age of volcanism in million years $[9,10]$. b) For readability, we only report the most recent volcanic ages $(<1 \mathrm{Ma})$ along the Walvis chain. Hotspot tracks deduced from rotation poles $[9,24,25]$ are also reported for comparison (see text). In both maps, the $2500 \mathrm{~m}$ isobath (thin black line) marks the position of the ridge and volcanic islands, and the bold black line indicates the traces used to study the temporal evolution of buoyancy and volcanic fluxes along both chains. The filter parameters to obtain the swell map are $r=45 \mathrm{~km}$ and $R=350 \mathrm{~km}$ for the minimization and filtering (see [7] for details).

Fig. 3. Swell amplitude along the St. Helena (top) and Walvis (bottom) trends (see Figure 1), as a function of distance from the present-day hotspot location (upper $x$-axis). Available ages of volcanism (gray arrows and numbers in Ma $[9,10])$ and calculated ages assuming a constant velocity $\left(29 \mathrm{~mm} \mathrm{yr}^{-1}\right)$ for the 
506

508

509

510

511

512

513

514

515

African plate (lower $x$-axis) are also shown along the horizontal axis.

Fig. 4. Calculated buoyancy (gray) and volcanic (black) fluxes for the St. Helena (top) and Walvis (middle) chains, as a function of the interpolated age of active volcanism (see text). Gray arrows point the secondary maxima at 38 and $54 \mathrm{Ma}$ in the Walvis buoyancy flux (see discussion). For comparison, the buoyancy and volcanic flux for Hawai'i are given in the bottom graph (from [5]). Note the change in vertical scale, for readability.

13 Table 1. Total volumes and volume fluxes of volcanic material and swell for Circe, St. Helena and Walvis (this study), and Hawai'i (from [5]). Note that the total fluxes here are calculated as a mean flux along the chain. 


\section{Figure 1}

Click here to download Figure: Adam_Fig1.pdf

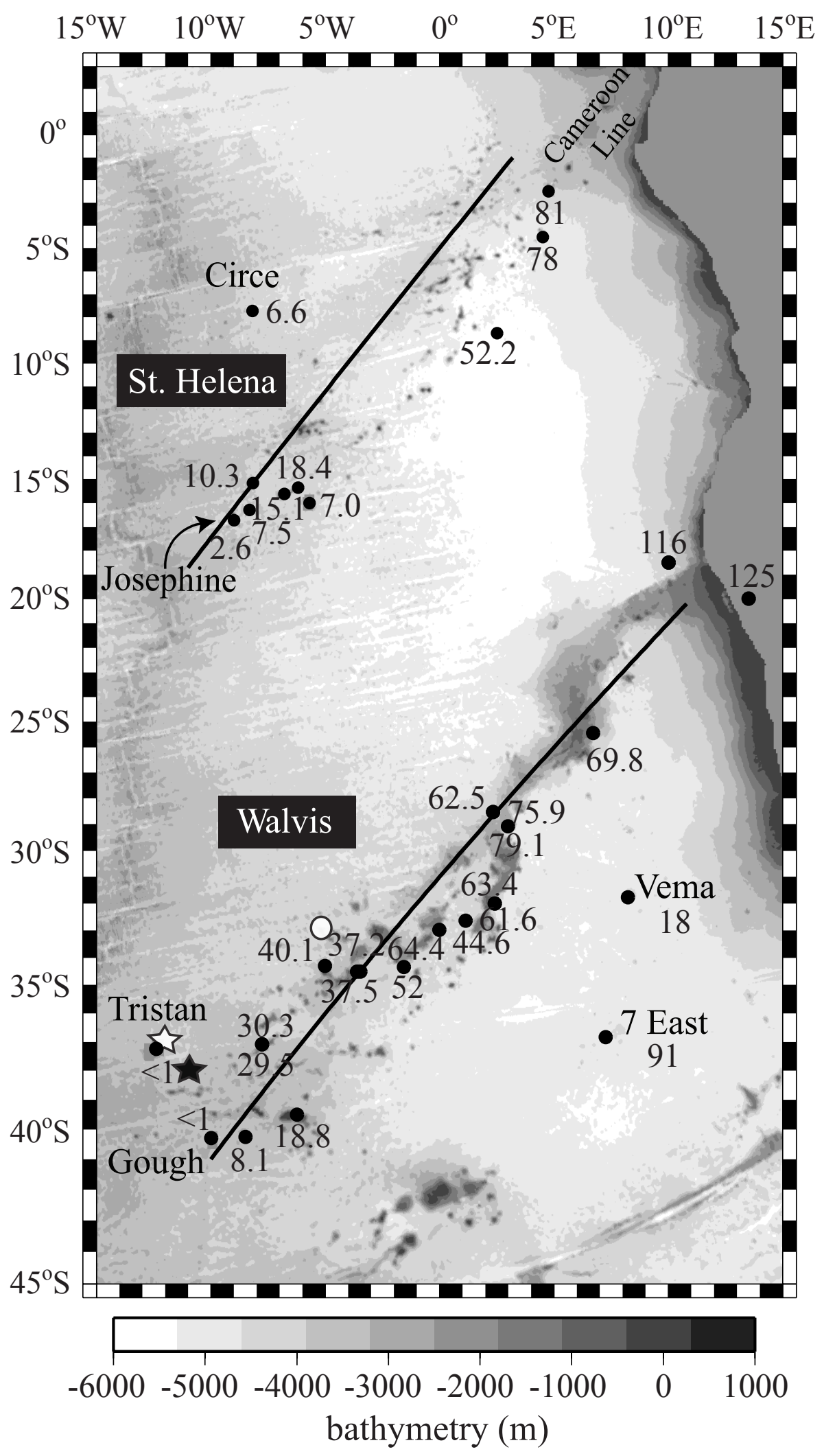




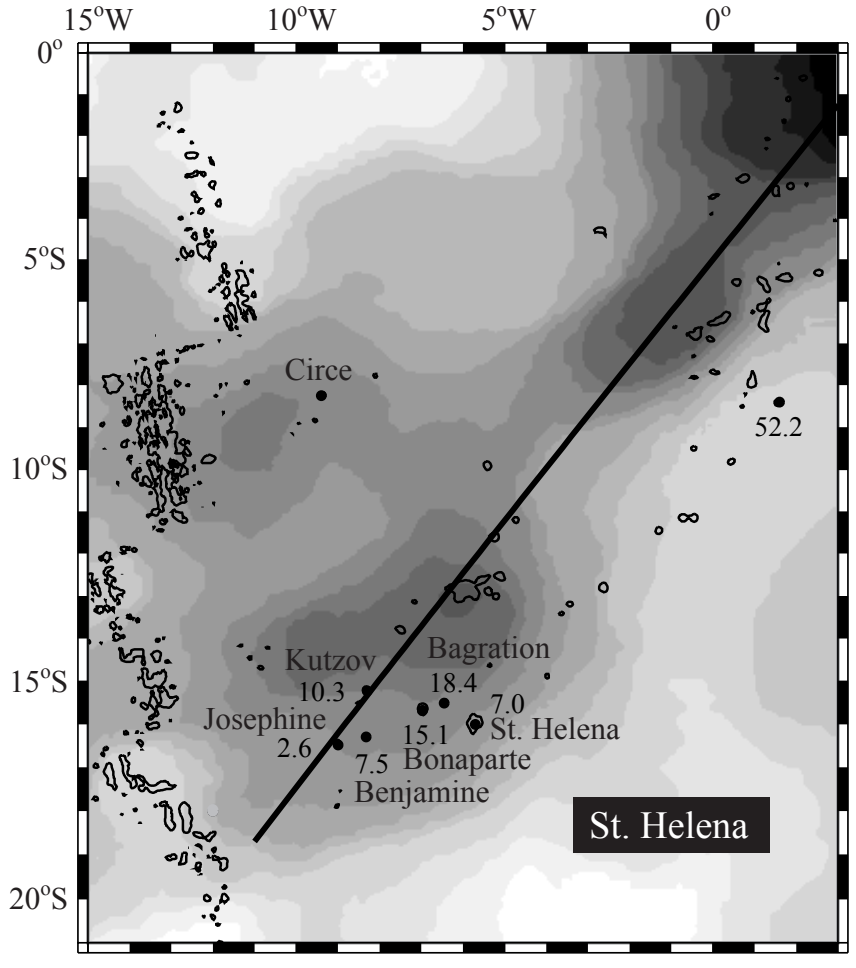

(a)

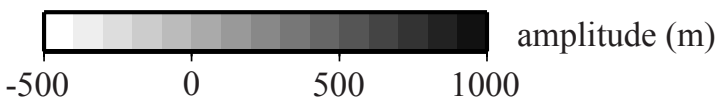

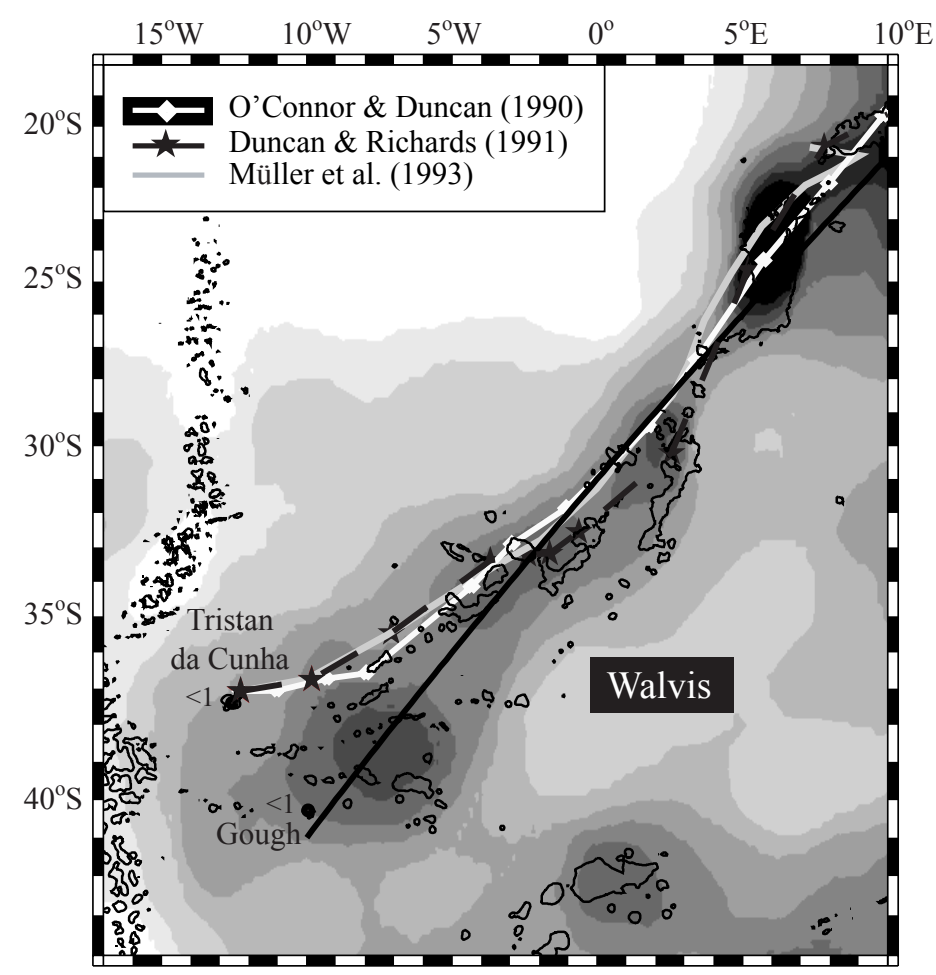

(b)

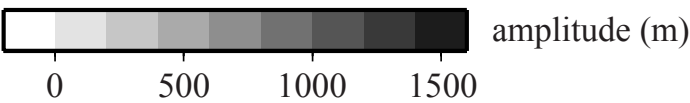




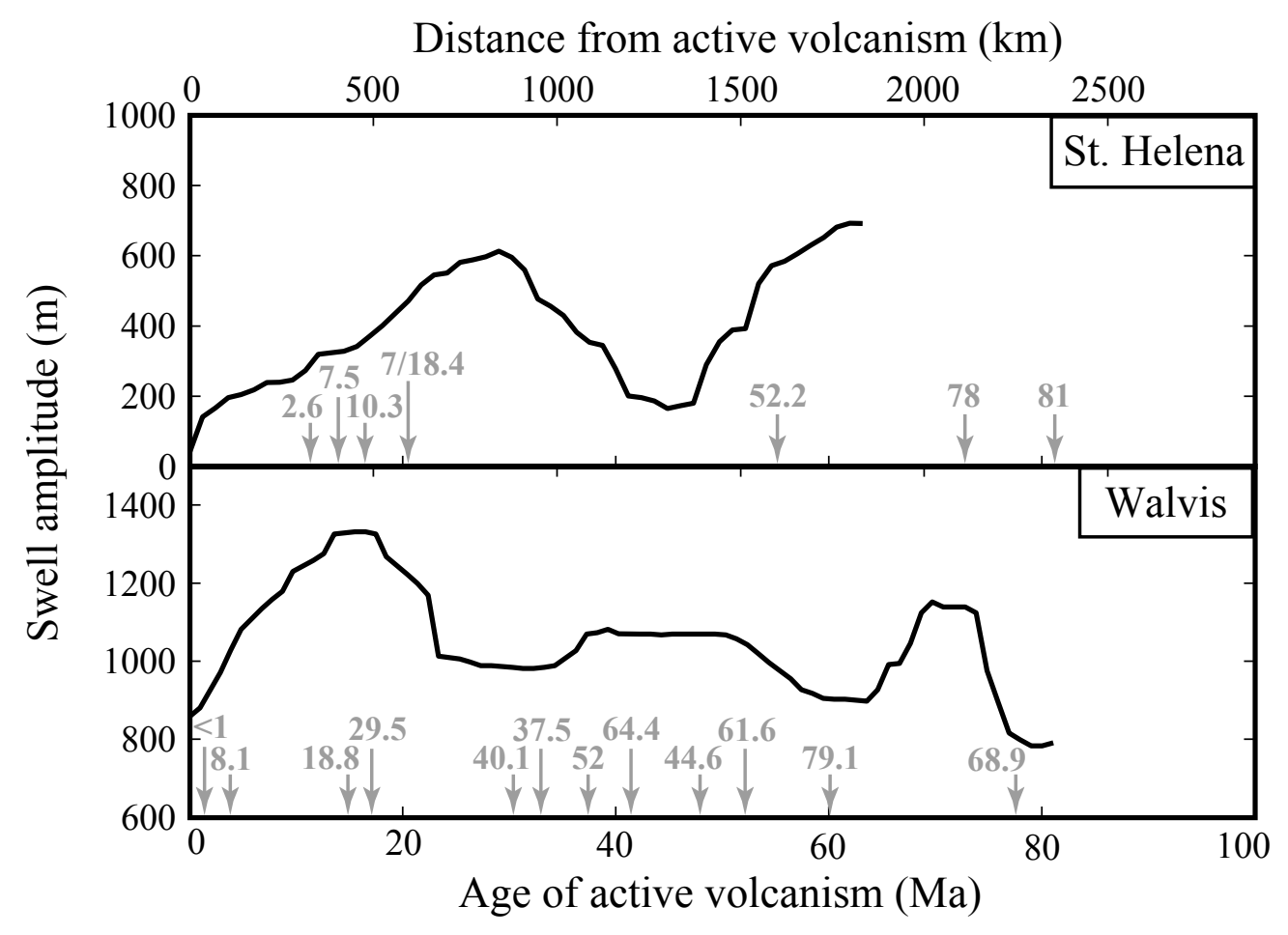




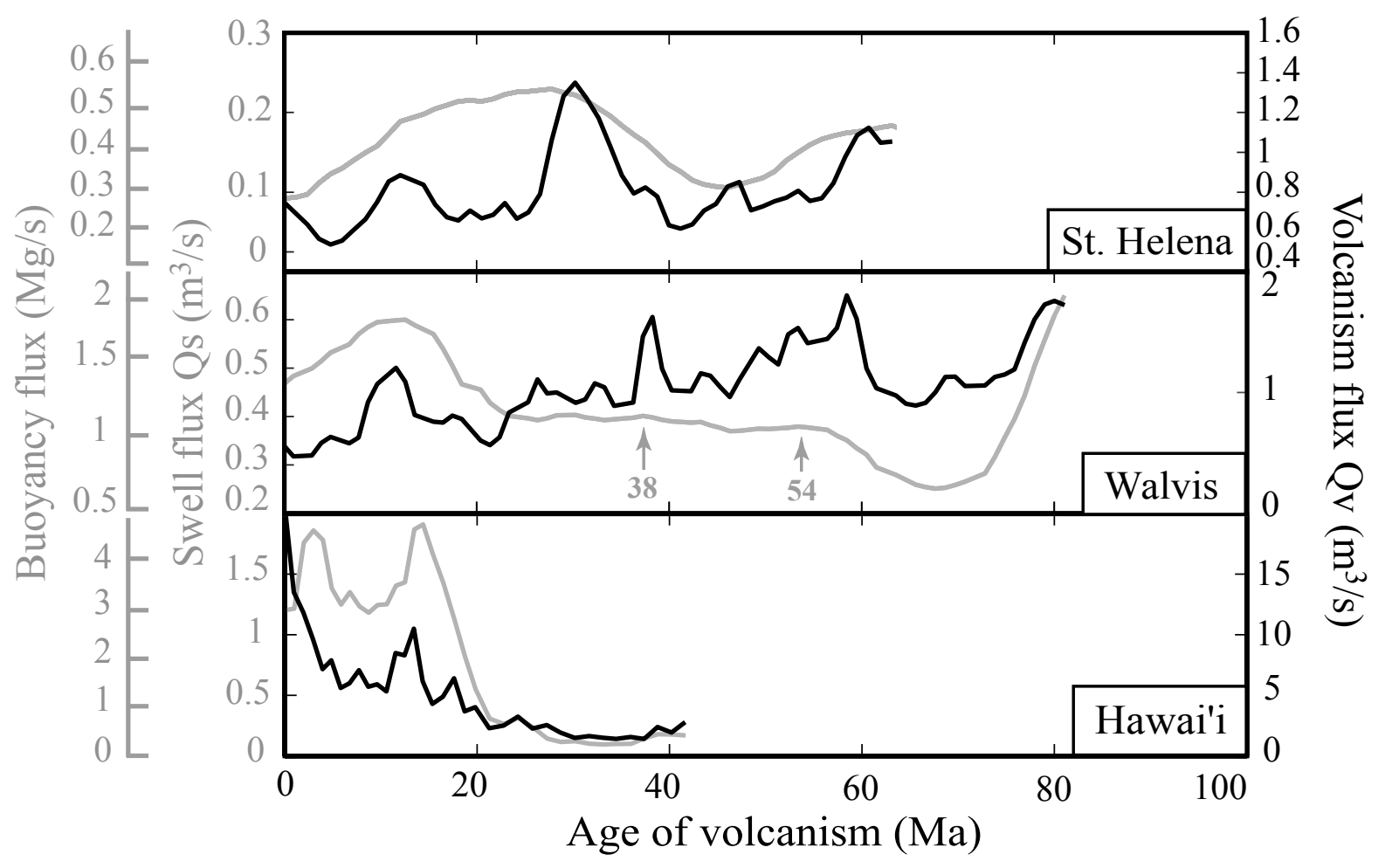




\begin{tabular}{l|c|c|c|c|c}
\hline \hline & $\begin{array}{c}\text { Volcanic volume } \\
\left(\times 10^{5} \mathrm{~km}^{3}\right)\end{array}$ & $\begin{array}{c}\text { Swell volume } \\
\left(\times 10^{5} \mathrm{~km}^{3}\right)\end{array}$ & $\begin{array}{c}\text { Volcanic flux } \\
\left(\mathrm{m}^{3} \mathrm{~s}^{-1}\right)\end{array}$ & $\begin{array}{c}\text { Swell flux } \\
\left(\mathrm{m}^{3} \mathrm{~s}^{-1}\right)\end{array}$ & $\begin{array}{c}\text { Buoyancy flux } \\
\left(\mathrm{Mg} \mathrm{s}^{-1}\right)\end{array}$ \\
\hline Circe & - & 0.65 & - & 0.09 & 0.22 \\
St. Helena & 11.1 & 2.33 & 0.76 & 0.16 & 0.37 \\
Walvis & 21.4 & 8.79 & 1.00 & 0.41 & 0.96 \\
Hawai'i & 61.8 & 10.0 & 4.70 & 0.76 & 1.75 \\
\hline \hline
\end{tabular}

